Полянская И. Л., Филисюк Н. В.

I. L. Polyanskaya, N. V. Filisyuk

ИССЛЕДОВАНИЕ ВЛИЯНИЯ ДЛИТЕЛЬНОСТИ ИСКУССТВЕННОГО СТАРЕНИЯ НА СВОЙСТВА СТАЛИ

\title{
STUDY OF DURATION INFLUENCE OF ARTIFICIAL AGING ON THE PROPERTIES OF STEEL
}

Полянская Ирина Леонидовна - кандидат технических наук Уральского государственного университета путей сообщения (филиал в г. Тюмени) (Россия, Тюмень). E-mail: polyanskaya_il@inbox.ru.

Ms. Irina L. Polyanskaya - PhD in Engineering, Ural State Railway Transport University (affiliated in Tyumen) (Russia, Tyumen). E-mail: polyanskaya_il@inbox.ru.

Филисюк Нина Васильевна - старший преподаватель Тюменского индустриального университета (Россия, Тюмень). E-mail: klv@mail.ru.

Ms. Nina V. Filisyuk - senior lecturer, Industrial University of Tyumen (Russia, Tyumen). E-mail: klv@mail.ru.

Аннотация. В статье представлены результаты исследований искусственного деформационного старения трубных сталей. Изменения температуры ускоряют процессы старения стали, в результате которых происходит изменение ее микроструктуры. Определено влияние деформационного старения на механические свойства стали при испытаниях на ударную вязкость.

Summary. The article presents the studies of artificial strain aging of pipe steels. Changes in temperature accelerate the aging process, which resulted in a change of its microstructure. The effect of strain aging on the mechanical properties of the steel in toughness tests is determined.

Ключевые слова: деформационное старение, дислокации, охрупчивание, перестаривание, трубная сталь, ударная вязкость, температура старения.

Key words: strain aging, dislocation, embrittlement, overaging, pipe steel, toughness, aging temperature.

УДК 621.791 .011

\section{Введение}

Старение металла - это изменение его свойств во времени при комнатной температуре при длительном вылеживании (естественное старение) или при повышенных температурах в ходе специальной термической обработки (искусственное старение), а также изменение свойств при вылеживании или эксплуатации при различных температурах после холодной пластической деформации. Имеется специальный класс сталей и сплавов, для которых старение является заключительной термической обработкой $[1 ; 8 ; 12]$.

Работы по изучению старения $\mathrm{Fe}-\mathrm{C}$ сплавов показали, что общая закономерность распада пересыщенного раствора аналогична закономерностям, наблюдаемым в цветных сплавах, при этом старение идет за счет внедрения примесей (углерода и азота).

В основном, изучают два вида старения:

1) Старение после закалки. Это явление связано с распадом пересыщенного твердого раствора, скорость которого определяется температурой старения, химическим составом стали и количеством дефектов кристаллического старения.

2) Деформационное старение. Это явление связано с изменением свойств во времени после холодной и пластической деформации. В зависимости от вида деформации различают статическое старение (сопровождается перераспределением атомов углерода и азота в твердом растворе после холодной деформации) и динамическое (перераспределение атомов происходит в процессе пластической деформации). 
Полянская И. Л., Филисюк Н. В.

ИССЛЕДОВАНИЕ ВЛИЯНИЯ ДЛИТЕЛЬНОСТИ ИСКУССТВЕННОГО СТАРЕНИЯ НА СВОЙСТВА СТАЛИ

При деформационном старении в стали появляется большое количество «свежих» дислокаций, которые при достаточной их подвижности способны взаимодействовать с атомами углерода и азота. Различают следующие стадии деформационного старения:

1) Первая стадия - увеличение количества атомов углерода и азота на дислокациях, которое приводит к уменьшению расчетных расстояний между точками закреплений дислокаций $\left(L_{C}\right)$, росту площадки текучести и упрочнению металла.

2) Вторая стадия - увеличение количества атомов углерода и азота на дислокациях, сопровождающееся дальнейшим упрочнением уже без изменения $L_{C}$ и длины площадки текучести.

3) Образование частиц устойчивой фазы. Эта стадия характеризуется значительным повышением предела текучести и охрупчиванием.

4) Коалесценция частиц устойчивой фазы, выделившихся на предыдущей стадии - характеризуется увеличением расчетных расстояний между точками закрепления дислокаций $L_{C}$ и, как следствие, снижением прочности. Именно эта стадия имеется в виду, когда говорят о перестаривании.

Кроме этого при длительном старении наряду с коалесценцией происходит смена мест преимущественного расположения частиц в связи с неизбежным различием уровня свободной энергии системы $[8 ; 12]$. В общем случае повышение длительности старения приводит к смене мест расположения частиц (карбидов железа) в следующей последовательности: матрица $\rightarrow$ дислокации $\rightarrow$ границы зерен.

\section{Методика проведения исследований}

Оценку склонности стали к деформационному старению проводили в соответствии с ГОСТ 7268-82*. Темплеты, представленные на исследование, вырезаны из трубопроводов, в которых в той или иной степени произошли процессы старения.

Из темплетов вырезались заготовки $12 \times 12 \times 250$ мм для изготовления ударных образцов и заготовки размерами $20 \times 5 \times 60$ мм (начальная ширина $\times$ толщина $\times$ рабочая длина). Заготовки с нанесенной на них сеткой подвергали деформации растяжением из расчета получения $(10 \pm 0,5) \%$ остаточного удлинения. Вид заготовок до и после деформации показан на рис. 1.

Согласно СНиП 2.05.06-85*, которым руководствуются при строительстве магистральных трубопроводов, ударную вязкость следует определять на образцах Шарпи (ГОСТ 9454-78*). Радиус концентратора напряжения у этих образцов составляет $(0,25 \pm 0,025)$ мм. Данное условие требует проведения более жестких испытаний, позволяющих гарантировать безопасность трубопроводов в процессе эксплуатации, для этого ударная вязкость при минимальной температуре эксплуатации трубопроводов на образцах Шарпи должна быть не менее 39,2 Дж/см². Минимальной температурой эксплуатации нефтепроводов в соответствии с ТУ 14-3-1698-2000 и СП 34-101-98 является температура $-5^{\circ} \mathrm{C}$.

Для измерения работы удара и ударной вязкости изготовлялись образцы с V-образным надрезом. Старение после деформации проводили при температуре $(250 \pm 10){ }^{\circ} \mathrm{C}$. Длительность старения составляла $0,1,10,100,500$ и 1000 ч.

После этого проводили испытания на растяжение и ударный изгиб. Испытания на растяжение проводили при температуре $+20^{\circ} \mathrm{C}$, испытания на ударный изгиб: $-40{ }^{\circ} \mathrm{C}$ на образцах Шарпи.

Поскольку при строительстве трубопроводов при укладке трубы в траншею имеет место холодная деформация, то при дальнейшей эксплуатации должно иметь место и деформационное старение [6; 8]. В связи с этим представляет интерес оценить склонность исследуемых сталей к деформационному старению.

Оценку склонности стали к деформационному старению проводили по ГОСТ 7268-82*. Суть метода заключалась в том, что определялась работа удара или ударная вязкость стали, подвергнутой холодной пластической деформации и искусственному старению, и сравнивалась с работой удара или ударной вязкостью стали в исходном состоянии с определением показателя склонности стали к старению С, который определялся как 


$$
\mathrm{C}=\frac{\mathrm{KC}-\mathrm{KCA}}{\mathrm{KCA}} \cdot 100
$$

где КС - среднее арифметическое значение ударной вязкости в исходном состоянии; КСА - среднее арифметическое значение ударной вязкости стали после старения.

a)

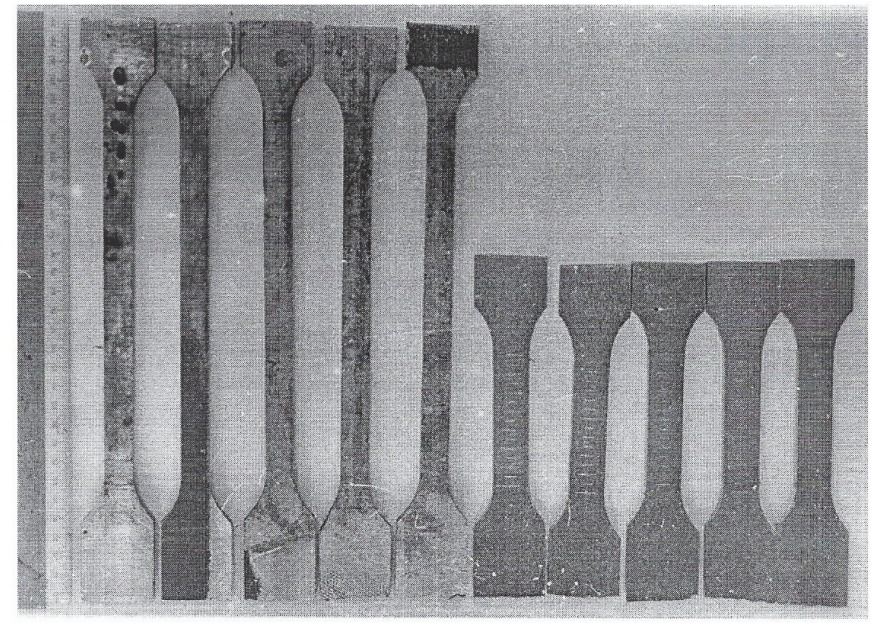

б)

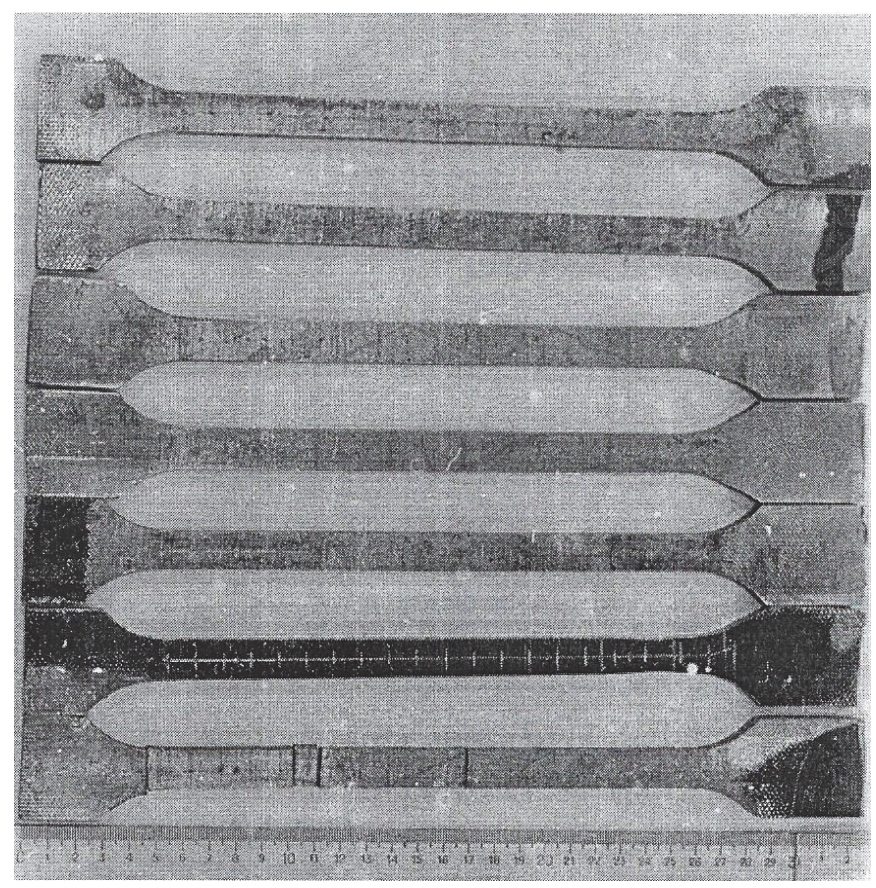

Рис. 1. Вид образцов для испытания склонности стали к деформационному старению:

a - исходные заготовки; б - вид заготовок после деформации растяжением $10 \%$

Сравнивались между собой только те результаты, которые получены при одном и том же способе деформации заготовок на одинаковых типах образцов. Искусственное старение проводили при температуре $(250 \pm 10)^{\circ} \mathrm{C}$ в течение 1 ч с последующим охлаждением на воздухе.

Схема вырезки образцов из трубы представлена рис. 2.

Данные, полученные при измерении, подтверждаются исследованиями микроструктуры, т.к. известно, что изменения проходят на уровне тончайших микроскопических структур.

Для оценки изменений применяли качественный и количественный анализы. 


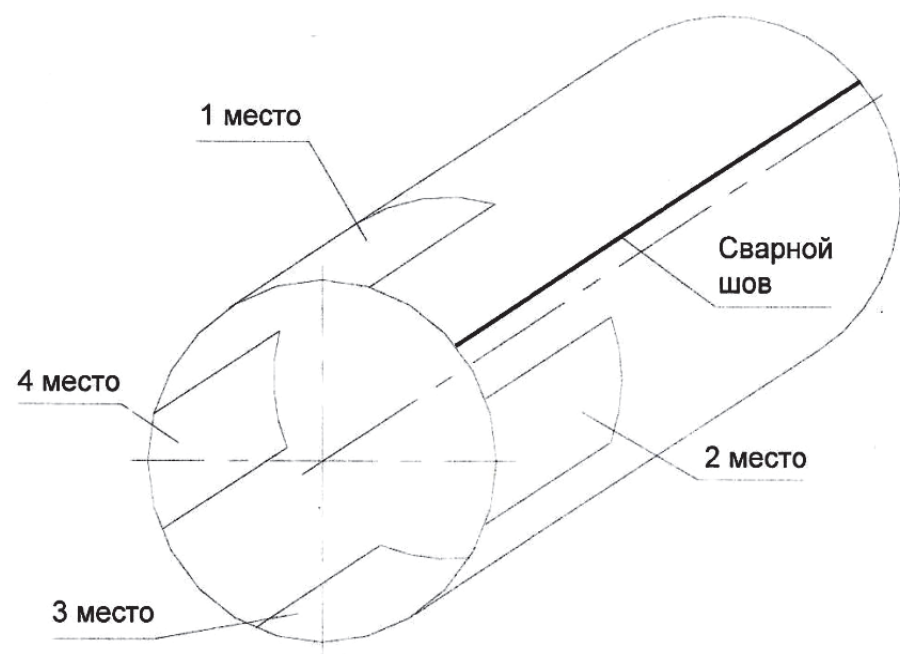

Рис. 2. Схема вырезки заготовок из трубы

Качественный анализ микроструктуры включал в себя оценку таких показателей, как форма, размер и границы зерен, выделения на границах зерен.

Количественный структурный анализ включал определение процентного содержания этих зерен путем вычисления занимаемой ими площади методом точечного счета. Исследования проводились в пяти партиях образцов. Подсчет проводили в пяти полях зрения шлифов из каждой опытной партии [11].

\section{Результаты исследований}

Основой резкой текучести является быстрое увеличение числа подвижных дислокаций в начале пластического течения. Для их появления требуется выполнение двух условий:

1) в исходном состоянии в образце число подвижных дислокаций должно быть очень малым;

2) число подвижных дислокаций должно быстро увеличиваться по тому или иному механизму в самом начале деформации.

Резкое увеличение числа подвижных дислокаций возможно:

1) за счет разблокировки ранее закрепленных дислокаций (отрыв от примесных атмосфер, обход частиц второй фазы поперечным сложением и т.п.);

2) за счет образования новых дислокаций;

3) за счет размножения в результате взаимодействия.

Недостаток подвижных дислокаций в исходном образце может быть связан либо с высоким совершенством структуры, либо с закреплением имеющихся дислокаций. Такое закрепление может быть достигнуто образованием примесных атмосфер на дислокациях в процессе старения.

Разрушение образцов происходит по типу, который называют «конус-чашечка». Разрушение «конус-чашечка» занимает промежуточное место между хрупким и вязким разрушениями. Часто под термином вязкого разрушения понимают именно этот тип разрушения.

После механических испытаний исследуемые образцы имеют хорошо выраженную шейку (см. рис. 3).

Макроскопическая картина разрушения при испытании на растяжение с образованием излома «конус-чашечка» выглядит следующим образом: по мере увеличения нагрузки образец удлиняется и уменьшается в сечении, причем изменения равномерно распределяются по рабочей длине образца; на определенном этапе процесса (обычно после достижения максимального значения нагрузки) наблюдается потеря устойчивости деформации и образуется локальное уменьшение сечения образца - шейка; в результате этого во внутренних областях образца возникает объемное напряженное состояние - трехосное растяжение, накладывающееся на внешнее осевое растяже- 


\section{Ученые записки \\ Комсомольского-на-Амуре государственного технического университета

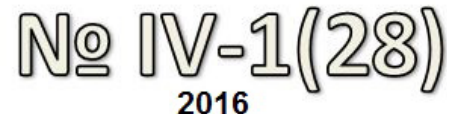

ние; заключительный этап процесса - разрыв образцов. Разрушение начинается с образования мелких пустот - пор, которые, сливаясь, образуют центральную трещину.

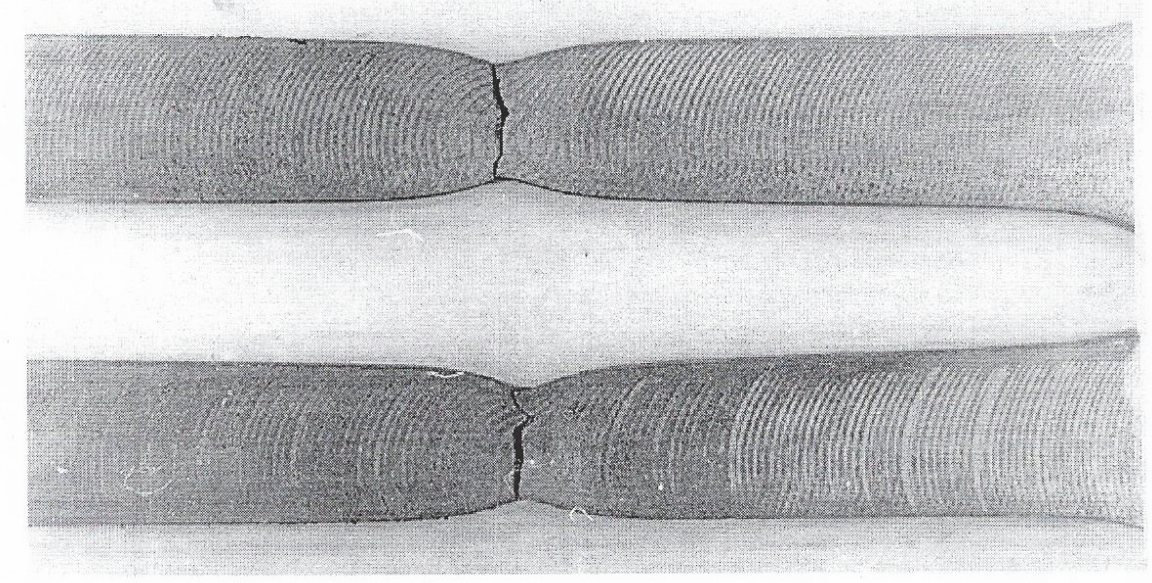

Рис. 3. Вид образцов после испытания на растяжение

В большинстве случаев трещина появляется в центре сечения, а затем начинает распространяться в обе стороны по направлению к боковой поверхности, образуя дно будущей чашечки. По приближении к поверхности трещина поворачивает под углом $\approx 45^{\circ}$ к первоначальному направлению и выходит на поверхность, образуя коническую часть излома.

Диаграммы растяжения состаренных образцов показаны на рис. 4. Диаграммы 1 и 1' соответствуют образцу, который после деформации на 10 \% без старения был подвергнут повторному нагружению, диаграмма 2 - образцу, который после деформации был состарен в течение 1 ч при $250{ }^{\circ} \mathrm{C}$. Как видно из рис. 4 , на диаграмме появляется площадка текучести длиной $l_{1}$. При увеличении длительности старения до 10 ч на диаграмме появляется зуб текучести, длина площадки текучести и предел текучести возрастают. Эти изменения говорят о том, что при увеличении длительности старения с 1 до 10 ч количество точек закреплений дислокаций возросло, а расчетное расстояние между точками закрепления $L_{C}$ уменьшилось.

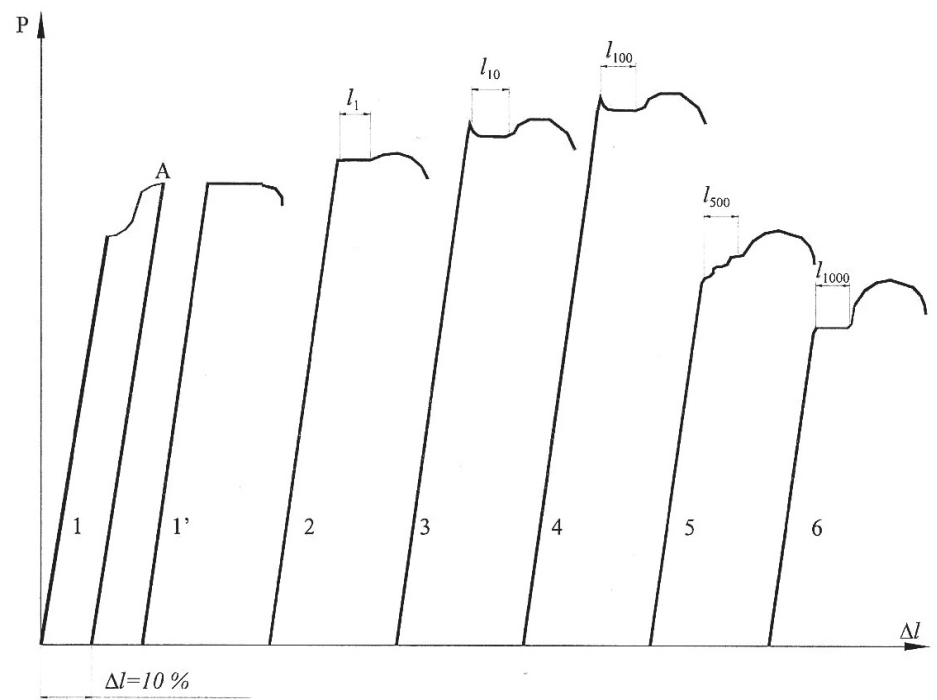

Рис. 4. Диаграммы растяжения состаренных образцов с различными режимами старения: 1 - деформация $10 \%$; 1 ' - повторное нагружение 1 -го образца; 2 - деформация $10 \%+250{ }^{\circ} \mathrm{C} \times 1$ ч; 3 - деформация $10 \%+250{ }^{\circ} \mathrm{C} \times 10$ ч; 4 - деформация $10 \%-250{ }^{\circ} \mathrm{C} \times 100$ ч; 5 - деформация $10 \%+250{ }^{\circ} \mathrm{C} \times 500$ ч; 6 - деформация $10 \%+250{ }^{\circ} \mathrm{C} \times 1000$ ч; $l_{1}, l_{10}, l_{100}, l_{500}-$ длины площадок текучести; $l_{1}<l_{10}, l_{10}=l_{100}=l_{500}$ 
Полянская И. Л., Филисюк Н. В.

ИССЛЕДОВАНИЕ ВЛИЯНИЯ ДЛИТЕЛЬНОСТИ ИСКУССТВЕННОГО СТАРЕНИЯ НА СВОЙСТВА СТАЛИ

При длительности старения 100 ч достигается максимальный эффект упрочнения, а длина площадки текучести не изменяется. Это свидетельствует о том, что на дислокациях сформировалась устойчивая фаза. Скорее всего, это цементит $\mathrm{Fe}_{2} \mathrm{C}$.

При длительности старения 500 ч предел текучести уменьшается. Это свидетельствует о том, что началась коалесценция карбидных частиц (рост более крупных частиц за счет растворения мелких). В результате этого процесса количество точек закреплений на дислокациях уменьшается, а прочность падает. Иначе говоря, при старении 500 ч происходит перестаривание стали. То же наблюдается при старении в течение 1000 ч.

Характер диаграммы растяжения перестаренного образца существенно отличается от других диаграмм: во-первых, на диаграмме растяжения отсутствует зуб текучести; во-вторых, на кривой наблюдается несколько площадок текучести.

Все это однозначно свидетельствует об уменьшении количества точек закреплений на дислокациях.

Микроструктурный анализ показывает, что при длительном старении происходит смена мест выделений карбидных частиц [11]. На рис. 5, а показана структура стали после старения в течение 100 ч. Как видно из рис. 5, $a$, в объеме зерен имеются отдельные черные точки (карбиды железа). На границах зерен карбида железа практически нет.

a)

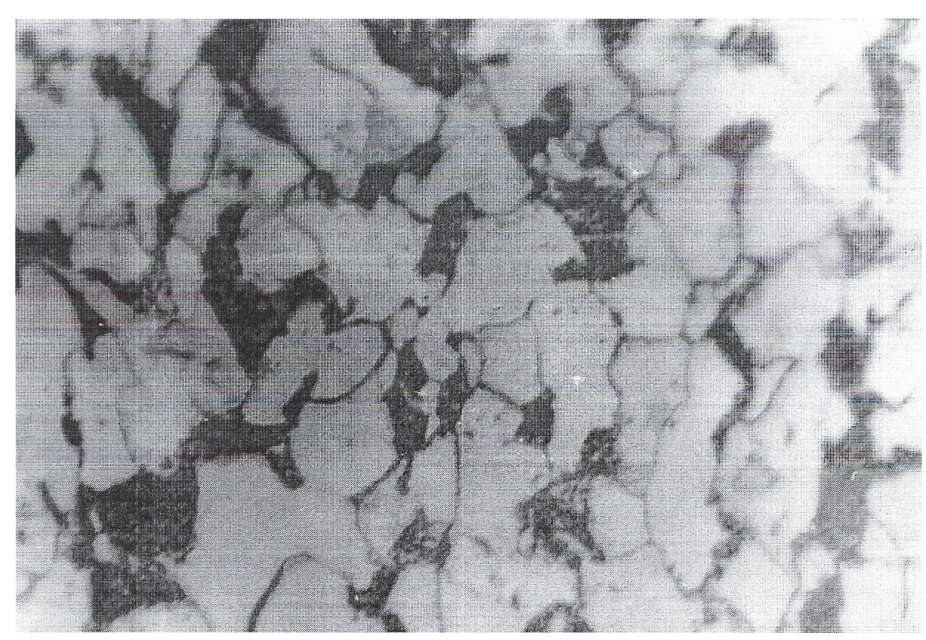

б)

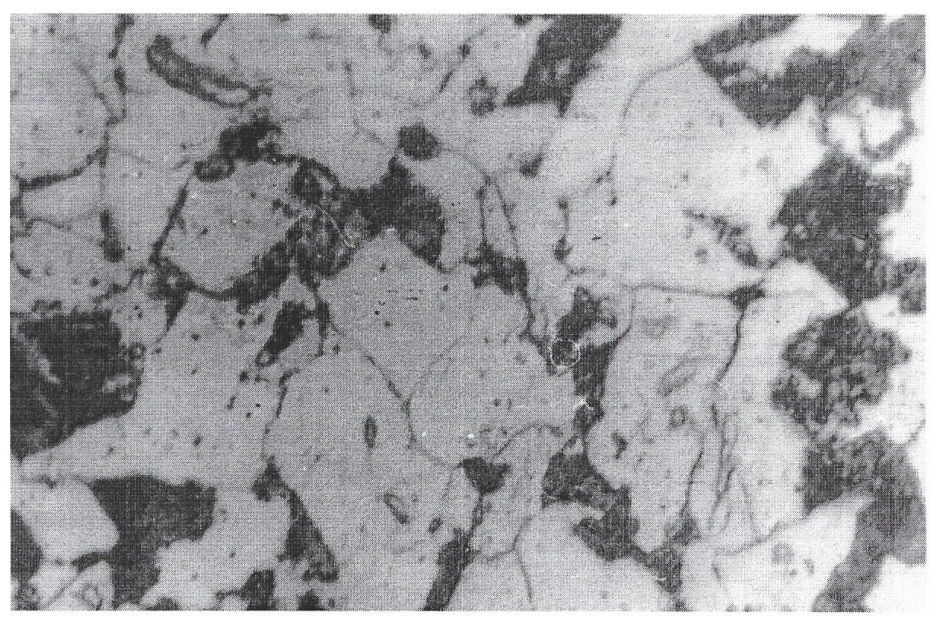

Рис. 5. Микроструктура стали после старения в течение 100 ч (а) и 500 ч (б)

На рис. 5, 6 показана структура стали после старения в течение 500 ч. Как видно из рис. 5,6 , количество цементитных частиц в объеме зерен возросло. Возросло и количество выделений на границах зерен. Необходимо отметить, что карбидные частицы, видимые на рис. 5 в объ- 
еме зерен, на самом деле находятся на дислокациях. Просто дислокации в данном увеличении не видны. Увеличение количества карбидных частиц при старении в течение 500 ч по сравнению со старением в течение 100 ч - кажущееся явление.

Данный эффект обусловлен не увеличением количества, а увеличением размеров карбидов (коалесценцией), в результате чего невидимые ранее частицы становятся видимыми. В целом же плотность выделений при увеличении длительности старения уменьшается, о чем свидетельствует снижение прочности стали.

Результаты испытаний на динамический изгиб приведены в табл. 1. Как видно из данных, приведенных в табл. 1, старение приводит к охрупчиванию стали, причем величина $K V C^{40}$ практически не зависит от длительности старения до 500 ч. При дальнейшем старении стали ударная вязкость возрастает.

Таблица 1

Значения ударной вязкости $K V C^{-40}$, Дж/ $\mathrm{cm}^{2}$

\begin{tabular}{|c|c|c|c|c|c|c|}
\hline \multirow{2}{*}{ Номер испытания } & \multicolumn{7}{|c|}{ Длительность старения, ч } \\
\cline { 2 - 7 } & 0 & 1 & 10 & 100 & 500 & 1000 \\
\hline 1 & 24,0 & 1,25 & 1,25 & 3,75 & 1,75 & 13,1 \\
\hline 2 & 19,8 & 1,25 & 1,50 & 1,25 & 2,75 & 14,9 \\
\hline 3 & 21,6 & 3,75 & 4,75 & 1,25 & 1,50 & 8,5 \\
\hline
\end{tabular}

Исследования, проведенные нами ранее, показали, что при длительности эксплуатации (более 30 лет) процессы старения развиваются настолько, что предел текучести стали становится ниже значений, регламентированных ГОСТ 19282-73*. Результаты этих исследований приведены в табл. 2.

Таблица 2

Результаты испытаний механических свойств стали 14ХГСА после 30 лет эксплуатации

\begin{tabular}{|c|c|c|c|}
\hline \multirow[t]{2}{*}{ Номер места } & \multicolumn{3}{|c|}{ Параметр } \\
\hline & Предел прочности $\sigma_{\text {в }}$ МПа & Предел текучести $\sigma_{\text {т }}$ МПа & Удлинение $\delta, \%$ \\
\hline $\begin{array}{c}\text { Значение по ГОСТ } \\
\text { 19282-73* (попе-- } \\
\text { речные образцы) }\end{array}$ & 490 & 345 & 22 \\
\hline \multirow{2}{*}{ 1-е место } & $495 \ldots . .505$ & $327 \ldots 331$ & 24 \\
\hline & $500 \ldots 507$ & $340 \ldots 345$ & 24 \\
\hline \multirow{2}{*}{ 2-е место } & $472 \ldots 474$ & $305 \ldots 321$ & 25 \\
\hline & $485 \ldots 495$ & $325 \ldots 327$ & 24 \\
\hline \multirow{2}{*}{ 3-е место } & $490 \ldots 506$ & $338 \ldots 341$ & 27 \\
\hline & $\overline{505 \ldots 510}$ & $345 \ldots 347$ & $\overline{25}$ \\
\hline \multirow{2}{*}{ 4-е место } & $506 \ldots 512$ & $340 \ldots 342$ & 26 \\
\hline & $515 \ldots 520$ & $345 \ldots 348$ & 25 \\
\hline
\end{tabular}

Примечание. В числителе даны свойства стали вдоль прокатки, в знаменателе - поперек прокатки

В табл. 3 приводятся значения ударной вязкости при различных температурах.

Обращает на себя внимание очень высокий уровень ударной вязкости у исследуемой стали. Образцы не разрушались при испытании при температуре $-80{ }^{\circ} \mathrm{C}$, и даже при $-180{ }^{\circ} \mathrm{C}$ уровень ударной вязкости близок к значениям, которые регламентируются ГОСТом для этой стали при температуре $-40{ }^{\circ} \mathrm{C}$. Высокие значения ударной вязкости обусловлены особенностями разрушения при испытаниях, которые, в свою очередь, зависят от структуры стали. 
Полянская И. Л., Филисюк Н. В.

ИССЛЕДОВАНИЕ ВЛИЯНИЯ ДЛИТЕЛЬНОСТИ ИСКУССТВЕННОГО СТАРЕНИЯ НА СВОЙСТВА СТАЛИ

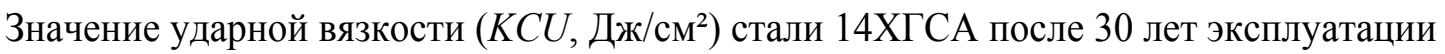

\begin{tabular}{|c|c|c|c|c|c|c|}
\hline \multirow{2}{*}{$\begin{array}{l}\text { Номер } \\
\text { места }\end{array}$} & \multicolumn{5}{|c|}{ Температура испытания, ${ }^{\circ} \mathrm{C}$} & \multirow{2}{*}{$\begin{array}{c}\text { Значение по } \\
\text { ГОСТ 19282-73* }\end{array}$} \\
\hline & +20 & -40 & -60 & -80 & -180 & \\
\hline \multirow[t]{2}{*}{ 1-е место } & Не сломался & Не сломался & Не сломался & Не сломался & 27,5 & \multirow{8}{*}{$\begin{array}{c}\text { При -40 C } \\
\text { ударная } \\
\text { вязкость >39 }\end{array}$} \\
\hline & $78 \ldots 95$ & $51,2 \ldots 60$ & $27,5 \ldots 38,7$ & - & - & \\
\hline \multirow[t]{2}{*}{ 2-е место } & Не сломался & Не сломался & Не сломался & $122,5 \ldots 140,5$ & 30 & \\
\hline & $115 \ldots 120$ & $55 \ldots 75$ & $39 \ldots .42$ & - & - & \\
\hline \multirow[t]{2}{*}{ 3-е место } & Не сломался & Не сломался & Не сломался & Не сломался & 35 & \\
\hline & $85 \ldots 95$ & $48 \ldots 70$ & $30,5 \ldots 38$ & - & - & \\
\hline \multirow[t]{2}{*}{ 4-е место } & Не сломался & Не сломался & Не сломался & Не сломался & 29,5 & \\
\hline & $76 \ldots 90$ & $57 \ldots 75$ & $26 \ldots 35$ & - & - & \\
\hline
\end{tabular}

Примечание. В числителе даны значения ударной вязкости вдоль прокатки; в знаменателе - поперек прокатки

\section{Выводы}

Проведенные исследования показывают, что в процессе длительной эксплуатации в металле труб прошли процессы старения, но уровень его свойств на сегодняшний день достаточно высокий, и он соответствует ГОСТ 19282-73* и СНиП 2.05.06-85*.

Однако необходимо иметь в виду, что процессы старения в металле будут развиваться дальше. Поэтому естественно встает вопрос, что ожидается в перспективе. В связи с этим представляется интересным проследить изменение свойств металла при искусственном старении. Повышение температуры ускорит процессы старения и позволит определить влияние различных стадий старения на свойства стали.

Необходимо отметить, что снижение прочности не только повышает вероятность разрушений, но и создает проблемы при ремонте трубопроводов, поскольку труба легко теряет устойчивость при небольших нагрузках.

Таким образом, полученные результаты говорят о том, что при длительной эксплуатации трубопроводов возможны два вида негативных изменений свойств сталей:

1) охрупчивание;

2) снижение прочности.

Снижение прочности трубы обусловлено двумя причинами:

1) утоньшением стенки трубы в результате коррозионных процессов;

2) перестареванием трубы.

Оба этих фактора оказывают большое влияние на прочность трубопроводов. Чтобы минимизировать потери разрушений трубопроводов в результате перестаревания необходимо после 20летнего срока эксплуатации проводить периодическую аттестацию трубопровода (рекомендуется один раз в 3 года) с целью определения изменения механических свойств металла и соответствие их нормативным документам.

\section{ЛИТЕРАТУРА}

1. Карнаухов, Л. А. Протектор буровых долот буровых / Л. А. Карнаухов, М. Л. Карнаухов // Обзорная информация ВНИИОЭНГ, сер. «Бурение». - Вып. 16. - М.: ВНИИОЭНГ, 1985. - 36 с.

2. Кисельман, М. Л. Износ и защита обсадных колонн при глубоком бурении / М. Л. Кисельман. - М.: Недра, 1971. - 208 c.

3. Криштал, М. А. Механизм диффузии в железных сплавах / М. А. Криштал. - М.: Металлургиздат, 1972. $-400 \mathrm{c}$.

4. Гумеров, А. Г. Старение труб нефтепроводов / А. Г. Гумеров, Р. С. Зайнуллин, К. М. Ямалеев, А. В. Росляков. - М.: Недра, 1995. - 223 с. 
5. ГОСТ 7268-82. Сталь. Метод определения склонности стали к деформационному старению по испытанию на ударный изгиб. - Введ. 01.01.1983. - М.: ИПК Изд-во стандартов, 2002. - 4 с.

6. Полянская, И. Л. Изменение свойств трубных сталей в процессе длительной эксплуатации / И. Л. Полянская, Н. И. Красовская // Сборник научных трудов SWorld. - Вып. 4. - Т. 16. - Одесса: КУПРИЕНКО СВ, 2013. - C. 24-26.

7. Кораблев, В. А. Отчет по научно-исследовательской работе: Исследование механизма образования, формы, размеров и площади карбидной фазы при обычном отпуске и тепловой обработке в вакууме на износостойкость и долговечность шарнирных подшипников из стали 95Х18Ш/ №78003824 от 01.12.1980.

8. Ячинский, А. А. Влияние структурно-фазового состава трубных сталей и их сварных соединений на сопротивление деформационному старению: дис. ... канд. техн. наук / А. А. Ячинский. - М., 2006. - 142 с.

9. Полянская, И. Л. Изучение термической и вакуумной обработки на износостойкость стали 40Х13, применяемой для изготовления ножей куттера / И. Л. Полянская, Д. Д. Байнашев, В. А. Кораблев // Материалы конференции национального первенства по научной аналитике открытого Европейско-Азиатского первенства по научной аналитике, Лондон, Великобритания, 15-20 марта 2012 г. - С. 69-73.

10. Полянская, И. Л. Изучение процессов, протекающих в закаленных углеродистых сталях при низком отпуске: монография / И. Л. Полянская, В. А. Кораблев. - Тюмень: РИО ФГБОУ ВПО «ТюмГАСУ», 2015. $-80 \mathrm{c}$.

11. Полянская, И. Л. Сталь 95Х18Ш и влияние на ее свойства тепловой вакуумной обработки / И. Л. Полянская, И. В. Шушарина // Сборник научных трудов ТюмГАСУ за 2014 год. В 2 т. Т.1. - Тюмень: РИО ТюмГАСУ, 2014. - С. 103-106.

12. Зорин, А. Е. Влияние упруго-пластической деформации на коррозионно-механические характеристики трубных сталей: автореф. дис. ... канд. техн. наук / А. Е. Зорин. - М., 2009. - 18 с.

13. ГОСТ 10705-80. Трубы стальные электросварные. Технические условия. - Введ. 01.01.1982. - М.: Стандартинформ, 2005. - $10 \mathrm{c}$. 